\title{
Online Engagement Using Moodle Based Platform among Mathematics Students
}

Femala Vellu, Siti Mistima Maat

To Link this Article: http://dx.doi.org/10.6007/IJARBSS/v11-i4/9688

DOI:10.6007/IJARBSS/v11-i4/9688

Received: 11 February 2021, Revised: 14 March 2021, Accepted: 26 March 2021

Published Online: 24 April 2021

In-Text Citation: (Vellu \& Maat, 2021)

To Cite this Article: Vellu, F., \& Maat, S. M. (2021). Online Engagement Using Moodle Based Platform among Mathematics Students. International Journal Academic Research in Business and Social Sciences, 11(4), 1239-1251.

Copyright: (C) 2021 The Author(s)

Published by Human Resource Management Academic Research Society (www.hrmars.com)

This article is published under the Creative Commons Attribution (CC BY 4.0) license. Anyone may reproduce, distribute, translate and create derivative works of this article (for both commercial and non-commercial purposes), subject to full attribution to the original publication and authors. The full terms of this license may be seen at: http://creativecommons.org/licences/by/4.0/legalcode

Vol. 11, No. 4, 2021, Pg. 1239 - 1251

Full Terms \& Conditions of access and use can be found at http://hrmars.com/index.php/pages/detail/publication-ethics 


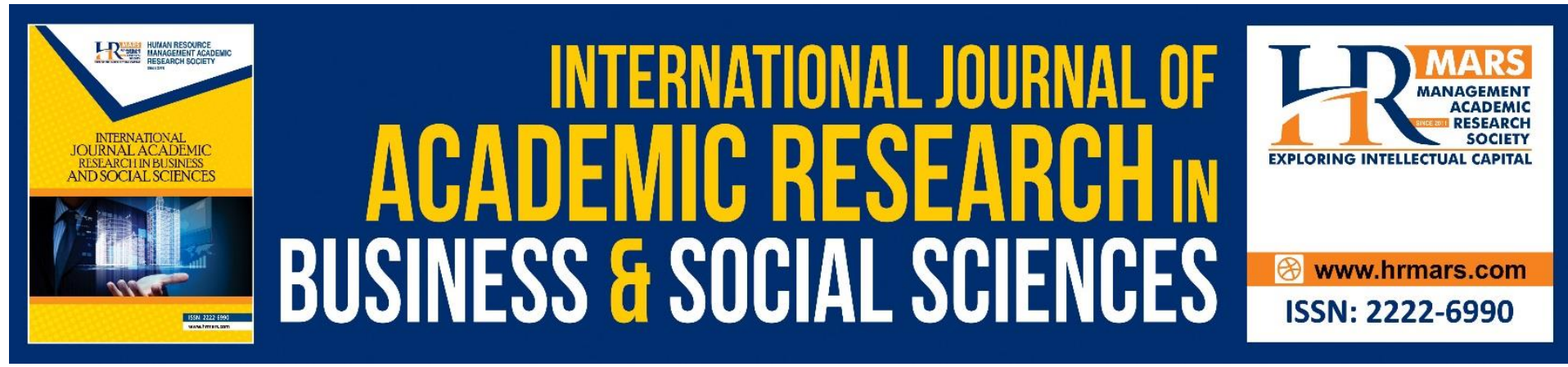

\title{
Online Engagement Using Moodle Based Platform among Mathematics Students
}

\author{
Femala Vellu, Siti Mistima Maat \\ Faculty of Education, University Kebangsaan Malaysia, Malaysia \\ Email: p101211@siswa.ukm.edu.my, sitimistima@ukm.edu.my
}

\begin{abstract}
The uses of technology make education more sophisticated especially higher education. Learning Management Systems (LMS) is a web-based technology to implement online teaching and learning easily. However, students' online engagement level in LMS still under question as it difficult to measure properly. This study was conducted to investigate students' engagement level in Moodle based platform (MBP) based on number of task posted and number of task viewed by students in MBP and the effects on students' learning outcome. The participants of the study were 33 undergraduate students who enrolled to an online 'The Psychology of teaching and learning in Mathematics Education' course. The descriptive statistic in this study reveals that students' engagement level is high for number of views in MBP compared to number of posts. While chi square test of independence results that number of views related with students' exam score. Then, the correlation analyzed using Spearman correlation coefficient shows there is positive correlation between number of views and students' exam score compare to number of posts by students on MBP. Thus, these findings may have implications for educator in higher education to manage multiple activities in MBP to improve students' learning particularly in mathematics.
\end{abstract}

Keywords: LMS Activities, Students' Engagement, Online Teaching and Learning, Higher Education

\section{Introduction}

In current informative society, digital and emerging technologies transformed the way teaching and learning conducted. The traditional teaching and learning via face to face method replaced with e-learning in many terms such as blended learning, distance learning, virtual learning and so on. Aldiab et al (2017) stated that e-learning is an instruction delivered on a digital device such as desktop computer, laptop computer, tablet or smart phone that intended to support learning. This clarifies that learning occurred with help of any electronic stuff can consider as an e-learning. In higher education, distance education was recognized as a tool to make accessible to the unreached and to allow a large portion of population to participate in education (Arthur-Nyarko, Agyei \& Armah, 2020). In distance learning, Learning Management Systems (LMS) used as a popular electronic medium to conduct online teaching and learning in higher education. LMS are web-based applications that used as an intermediary technology between teacher and learner to deliver e-learning (Safsouf et al., 
2010). Habeeb (2019) stated LMS is an easy way to learning participated by different levels students. While Bassam and Alshorman (2018) spotted some characteristic of LMS from previous studies. Firstly, it is easy access. Users of LMS can communicate with contain easily by connecting with internet at any time or any place. Secondly, in LMS educator can give feedback on the course, students, test, dates, results and everything that related with students' learning. Thirdly, allow multiple options for educators and students to communicate such announcements, e-mail, virtual classes and etc. Thus, LMS consider as a medium which can improve and facilitate communication. The fourth characteristic is educator able to follow-up students' uses of software and delivery of assignments and assigned activities in that platform. Fifth, students can develop their skills as learning such time management. Lastly, it takes account among different types of students. LMS provide content in several types such as audio, video, animation, images, games and others which work well for various intelligence participants.

Although online learning using LMS carries a lot of advantages, it still encountered some limitations. Vershitskaya et al (2020) outlined three types of obstacles found in university management developing countries while using e-learning. Firstly, the personal problems which related to personal characteristics, character and behavioral habits. Secondly, the relationship inhibitors which consist of internal variables that related with attitudes and opinions of consumers towards e-learning functions. Third type is contextual inhibitors which refer to external factors such as lacking of ICT skills and organization's support to use e-learning technologies.

While Muhtia, Suparno and Sumardi (2018) pointed the limitation of LMS such as tendency of students to get distracted, the limited account that can be opened on one computer at the same time, and low moderation of student comments and discussions. Other than that, these limitations also might cause due to the difficult task given by educators in LMS. To promote students' engagement, the behaviorist approach proposes to break down the certain skills into sub-objective associated with reinforcement which able to assimilated and mastered by students (Ouadoud et al., 2018).

Beyond the all challenges that might occur in LMS, there is an aspiration of every educators to motivate distance learners, promote learning, and improve learners' engagement, thus maximized learners' learning outcomes in terms of good grades (Cortez, 2020). Moodle Based Platform (MBP) is a medium that functions similar as LMS to carry out e-learning among university students. So, current study aimed to point out how long students engaged on LMS and its influences on students' outcome using selected MBP

\section{Online Engagement}

Student's engagement catch-all term most commonly used to describe a compendium of behaviors that involved students learning in terms of time, energy, and resources, students devote to activities designed to enhance learning at university (Redmond et al., 2018). Everett (2015) defined online engagement in context of behavior as multidimensional, interrelated, observable behavior, internal cognition and emotion. Although behavior is observable in online engagement, the cognition process of students still unpredictable. Fatawi et al. (2020) defined students' engagement in detail as it consists of three construct named behavioral, emotional and cognitive. Behavioral engagement refer to students' attention and effort being directly participated in learning process, asking question in public and spending time to accessing learning objects. While cognitive engagement covered focus, elaboration, explanation, self-regulated interest and psychological investment in learning. On the other 
hand, emotional engagement represents students' emotions such as anxiety, boredom, happiness, interest and passion. Students' engagement is refer to students' involvement in learning by performing interaction with educator, peers and content. Bolliger and Halupa (2018) stated in the article that simply reading post, emails and content not enough to consider as engagement. On the other hand, Deschaine and Whale (2017) said usually definition of students' engagement only focused on three element as mentioned affective, behavioral and cognitive. So, they pointed out the guideline to define students' engagement based on seven components from past studies. The first component is relevant. Here, students' engagement known as their understanding about topic and materials relevant to the academic program and future applications. Second is participatory. Apart from just present information, students have to actively involve in conversation and discussion related learning and interact with content and educator. Third is collaborative. As students work together to solve problem, practice and new skills and create product, they demonstrate their engagement in learning. Next component is challenging. Students usually engaged with activity when working to achieve reasonable and challenging goals. Fifth is students should receive specific feedback not only about what is correct and incorrect but the explanation including why it's correct or incorrect and also future suggestion. The sixth component of students' engagement is a friendly climate as learning occurs. Students comfort level and safe classroom where questions and input are encouraged improve students' engagement. Lastly, opportunity for students' connect with each other and instructors in learning community also known as a guideline for students' engagement.

The guideline widening the view about students' engagement and we can conclude that students' engagement effected by many implicit factors during learning occurred. Dumford and Miller (2018) said students' engagement can be effected by interaction with peers through collaborative learning and discussions, student-faculty interactions and effective teaching practices utilized by faculty. Although, numerous studies conducted based on students' engagement, there no works to represent the action taken based on the measured students engagement level due to difficulty to measure and what metrics to use (Moubayed et al., 2020). So, this study measured students' engagement level in MBP by analyzing number of task posed and viewed by students in MBP throughout the semester in one specific subject.

\section{Problem Statements}

The existence of new technologies take over the traditional teaching with new electronic teaching and learning (TL). Online TL challenges the teachers' competency to provide knowledge as well as learners' ability to gain the knowledge. But the question is does the online learning platform enhances students' learning outcome? Study about LMS shows that student who used LMS almost twice as much as others scored well in exam. Therefore, LMS have positive correlation with students' achievement (Akay \& Koral Gumusoglu, 2020). While Chen, Lee and Garrido (2018) said researcher fail to correlate learning behavior and learning outcome due to the lack of learning outcome assessment.

LMS limited the evaluation on thinking and learning as the thinking style of the students not fully presented on online platform but it mostly measured the activity by selfassessment of the participants and analysis of log files (Lerche \& Kiel, 2018). Pham and Tran (2020) encouraged the student to use e-learning system during learning program to increase the educational result because this study found that the more time of using e-learning system the better the learning outcome of students. This became the core factor that learning 
outcome of students is actually based on students' engagement in online learning. Students engagement have positive effects on grade and persistence of students significantly (Kokoc, 2019) as like many researcher proved that high engagement level resulted in high achievement of students in exam. However, there is no works that show the action taken based on the measured engagement level as it has been difficult to properly measure students engagement and what metrics to use (Moubayed et al., 2020).

While Everett (2015) said multiple communication channel may be related to higher engagement and that students to students and instructor students communication are strongly correlated with higher students engagement with the course. MacKenzie (2019) said well-designed online courses promotes the individual practice by multiple type of interaction and serve function of students as tutor through the interaction as (1) students interact with the content and idea presented in the course material such as text, (2) students interact with instructors through feedback on assignments and discussion form and (3) students interact with students through discussion debate, discussion and collaboration on task. Based on this statement, current research interest to study about students' interaction with content in online learning to analyze students' engagement level and how does students content interaction related with students outcome. In this study, students' interaction with content is studied based on number of task posted and number of task viewed by students in MBP.

This study is guided by the following research questions:

1) What is the level of students' engagement in Moodle based platform based on number of posted and viewed task in Moodle based platform?

2) Is the students' number of posts and number of views in Moodle based platform related with students' learning outcome?

3) What is the relationship between number of posted and viewed task by students in Moodle based platform and students' achievement?

\section{Objectives}

The objectives of the study are:

1) To identify the level of student's engagement in Moodle based platform based on number of posted and viewed task in Moodle based platform.

2) To identify the relation between student's activities in Moodle based platform and students' learning outcome.

3) To determine the correlation between student's activities in Moodle based platform and students' learning outcome.

\section{Methodology}

Sample

The participants of the study were the 33 postgraduate students selected via purposive sampling. All participants enrolled on one of the compulsory course known as Psychology of teaching and learning in Mathematics Education. The majority of study's participants were 24 female and 9 male who completed and passed a prerequisites course of Psychology of teaching and learning in Mathematics Education last semester. The students participated in the course via MBP which designed by particular university to interact with content, educators and peers. This MBP is the official platform for this specific university to carry out continuous Teaching and Learning activities and online exams. This MBP using a learning method that involves students' active participation or involvement where students can do multiple activities such interact with educators, view peers' work, assignment 
submissions and so on. The students login into MBP using specific matric number given by university via laptops, desktop computers, smartphones and tablets.

\section{Procedures}

The Psychology of teaching and learning in Mathematics Education covered theory and model of teaching and learning in Mathematics education. The course had been offered by the university as one of the mandatory subject in Mathematics department. This course offered once in two semesters for students and common for all students across content, educator, structure and activities. This course conducted by educator in MBP for three hours in a week for 14 weeks. Each session, students learn on a particular topic related to course objective as planned by tutor according to the weeks. During the learning, tutor provided notes, videos and evaluation activities such as quizzes and assignments to students related with the weekly topic in MBP. The materials and assignments provided by tutors were organized according to the weekly topics and were available on MBP until the end of the semester.

Additionally, few forums were created based on the course in MBP for students to share, discuss and communicate with peers and educator as well. The final exam for this course also given to students via MBP in the form of multiple-choice and open ended questions. The exam evaluated by educators. The marks from forum, assignments, presentations and final exams consider as a students' outcome of this course.

\section{Data Collection and Analysis}

Data for quantitative study were collected via MBP based on students' activities and students' exam score from educator. The data were analyzed using descriptive and inferential statistics via SPSS 22. Descriptive statistics were used to examine participant's engagement based on students' activities. Whereas, inferential statistics were used examined whether the students' activities in MBP related with students' achievement or not and their relationship. The inferential statistics in this study performed after explored the assumption of the statistical test. The assumption of normality has been violated where the data for this study does not distribute normally. So as an alternative method, this study preferred non parametric test which is chi-square test of independence and spearman correlation to do the analysis.

\section{Students' Activity On MBP}

The data for each student was collected from MBP records. The MBP listed many variables and only two variables selected related with students' interaction on content. First variable selected is number of message or posts by students for forum. The second one is number of views by students. Number of view reflects the number of videos, uploaded notes and forum viewed by students on MBP.

\section{Students' Academic Performance}

The students' performance obtained based on their total course score at the end of the 14 weeks of semester. The total score of students constitute of students work such as group presentations and reports (30\%), article writing (25\%), 4 forums (20\%) and final exam (25\%). The score given by the course expert based on students' works. The students' exam score found in this study ranged from $50.34 \%$ (minimum score) to $80.73 \%$ (maximum score). 


\section{Findings}

\section{Participants' Achievement}

Analysis of the descriptive for students' achievement showed that admissible exam score ( $M=73.60, S D=5.57)$. Female students $(M=74.39, S D=3.86)$ achieved slightly higher exam scores compared to male $(\mathrm{M}=71.49, \mathrm{SD}=8.63)$. Yet, $\mathrm{t}$-test was used to compare girls' average exam score to boys. The difference of between female and male was not significant $t(9.22)=-$ $0.973, p=.355$.

\section{Participants' Engagement}

Descriptive statistics on students' engagement based on number of posts and number of views summarized in Table 1. Mean, mode, median and standard deviation were calculated for variables.

Table 1. Descriptive Statistics for students' engagement

\begin{tabular}{lcccc}
\hline & Mean & Median & Mode & SD \\
\hline 1.Number of views & 66.42 & 55 & 52 & 39.31 \\
2. Number of posts & 15.09 & 14 & 13 & 5.65 \\
\hline
\end{tabular}

The mean of number of views for 33 respondents was 66.42 with a standard deviation of 39.31. This meant that if all the respondents had the same number of view, they would have score 66.42 with + or - variation of 39.31. The mode was 52 . Then, the median of number of view was 55 which meant that half of respondent initially views 55 times or less than that and the other half of the respondents initially views 55 times or more.

On the other hand, the mean for number of post was 15.09 and the standard deviation 5.65 which is lower compare to number of view. This statistics meant that if all respondents had the same number of post, they would have score 15.09 with + or - variation of 5.65. The median shows half of the respondents initially posted 14 posts or less and the other half initially posted 14 or more posts.

As a conclusion, descriptive statistics ascertained that number of views for participants ( $M=66.42, S D=39.31$ ) reported more than number of posts $(M=15.09, S D=5.65)$. According to Motz et al. (2019), the educator rate the engagement of students in LMS based on students activities such assignment, attendance, participation and overall engagement. A student get negative engagement rate based on categories like not complete the assignments, never attend class and low participation. Based on this assumption, we can conclude that the engagement level for students in this study is high for number of views in MBP compared to number of posts. 


\section{Is The Students' Number Of Posts And Number Of Views In Moodle Based Platform Related With Students' Learning Outcome?}

To identify the number of posts and number of views related to exams score or not, Chi Square test of independence was conducted. The exam score for the students categorized according the grade as follows:

\begin{tabular}{cc}
\hline Score & Gred \\
\hline $85-100$ & $\mathrm{~A}$ \\
$75-84$ & $\mathrm{~A}-$ \\
$65-74$ & $\mathrm{~B}+$ \\
$60-64$ & $\mathrm{~B}$ \\
$55-59$ & $\mathrm{C}+$ \\
$45-49$ & $\mathrm{C}$ \\
\hline
\end{tabular}

While the level of engagement for student based on number of posts and number views rated based on the median. For variable number of views, frequency above median score which is 55 consider as high level of engagement. While for number of post frequency above median score 14 consider as high level of engagement. Based on this, the test of chi square for number of views and exam score resulted as $x^{2}(3)=12.847, p<0.01$ where the association between number of views and exam score was $\phi=0.52$ can be considered as large effect. This shows number of views related with students exam score. While result of chi square for number posts with exam score shows $x^{2}(3)=1.864, p>0.01$. This result indicates that number of posts do not related with students' exam score.

\section{What Is The Relation Between Achievement And Students' Engagement?}

1) Ho: There is no a significant relationship between number of post and students' exam score.

2) Ho: There is no a significant relationship between number of views and students' exam score.

Before conducted the correlation between variable number of views, number of posts and students' exam score, normality test was conducted. Normality test of Shapiro-wilk reported $p<0.05$ which means the normality of variables has been violated. As an alternative, this study used spearman correlation to identify the relations between variables. The results showed in below table.

Table 2: Spearman Correlation Coefficient with students' achievement

\begin{tabular}{ccc}
\hline Variable & Correlation & p-value \\
\hline Number of Post & 0.202 & 0.259 \\
Number of Views & 0.399 & 0.022 \\
\hline
\end{tabular}

The analysis resulted there is positive correlation between variable number of views and students' exam score. The correlation between two variable is $r(33)=0.399, p<0.05$. This shows there is a significant positive correlation between number of views and students exam score. But the value shows that relationship between both variable slightly weak. While the correlation between number of post and students' achievement shows that $r(33)=0.202$, 
$\mathrm{P}=0.259>0.05$ which means the null hypothesis was accepted. This indicates there is no significant correlation between number of post and students exam score.

\section{Discussions}

The predominant goal of MBP is to help learners achieve competence in enrolled course through interact with peers, educators and contents. Yet, there are many factors that determine learners' success or failures in a specific course. In this study, the concept of students' engagement based on number views and number of post was studied in relation to achievement of students.

\section{Number of Views}

The study revealed that number of views by students on peers' works, educators' notes and other contents in MBP have positive correlation between students' achievement. This shows that students who recorded higher number of views scored well in their exam. Higher number of views indicates students had higher engagement level of in MBP. Most of the study reported that the more the students interact with the online system, the greater the chance she or he will achieve higher level of performance (Karabiyik, 2019). Henrie et al. (2018) said it is possible that students revisit the pages long after they engaged in activity such as reviewing content before an exam. This statement supported by our findings and shows that students' achievement in the exam is actually based on the students' view on contents or notes on MBP. Student's view on the MBP might reflect their revision activity to enhance their knowledge level of specific course before their exam, quiz or any assessments.

Viewing in MBP refer to doing refers on contents and replying message or give a comment on others works after view the contents. Based on that, number of view by students in MBP is one of the acts of social interaction in MBP. Lu and Law (2012) reported that the more feedback learners provided to peer, the better their own performance. When a learner view and give a feedback or comment to peers' works, they engage in the activities by improve their cognitive where they became more critical and have better understanding about specific topic. This might be the reason behind the relationship of number of views by students in MBP to their exam score.

\section{Number of Posts}

The findings for this study show that the number of posts not correlated with the students' exam score. The correlation coefficient score, $r=0.02$ indicates there is a moderate positive correlation between number of post and students' achievement. But the significant level $p>0.05$ indicates there is no significant relation between both variables. This reflects that even though students post their work in MBP, their exam result not related with their activities of posted works.

This negative result may be due to some reasons. One of the possible reasons is students' motivation. Marikar and Jayarathne (2016) reported maintaining participant's interest and motivation part is lacking in e-learning platform. Mostly, the task or forum given by educator might be harder and students only post the task to accomplish the requirement of the course. This action of students will reduce the quality of posts in MBP and will not encourage students to gain more knowledge in specific topic. Other than that, lack of positive reinforcement in MBP after posted any task is might be a reason for students' limited involvement in posting task or learning materials in MBP. 
In addition, MBP is a self-contained learning where students need to watch all videos and refer to the materials on the MBP before post any task or come up with answer for exam. This is reflected by the finding of this study where the mean score for number of posts by students $(M=15.09)$ is less than number of views $(M=66.42)$. From the statistical result, we can conclude that viewing was more preferred by students and contribute more to students' achievement in exam compare to number of posts in MBP.

\section{Implications}

When involved in learning activities, students emphasize learning goals and they tend to see interactive experiences with peers and engaging in diverse knowledge sharing situations (Tseng et al., 2020). This study shows that number of views by students on contents, notes, peers works and forums has a positive correlation with their exam score. So, as an educator it is our responsibility to provide information, notes and multiple activities in MBP so that students can use this opportunity to improve their knowledge. According to Kotsiantis et al. (2013) implementation of real-time visual feedback mechanism in each students' activities could leverage intrinsic motivation and re-align students' effort. In MBP, educator might give feedback to students' activities. This will be a guide to all students who view the feedback and encourage them as well to improve their learning proses.

\section{Limitations}

There are some of limitations in this study. First, the participants of this study were homogenous where all of them postgraduates from Mathematics department. Other than that, this study used small sample size. Therefore participants may not adequate to representative for all students who using MBP in selected university. Students' education level, gender, experience, perceptions and expectation may differ from other group of students. Second, this study analyzed students' engagement based on number of views and number of posts only. There are many variables found on MBP such as attendance of students, students' computer skills, educators' role, students' perception and time duration spent in MBP excluded from this study.

\section{Proposed Future Work}

Further study suggested based on limitations found on this study. First, participants for future study should be selected from different disciplines to obtain more accurate result based on MBP. The heterogeneous group might help the researcher to find other variables or factors that influence students' engagement in MBP and students' achievement as well. Second, future study can be conduct by increasing the number of participants because small sample size might violate the normality of data and accuracy of the results. Third, future study can identify other variables that can be found in MBP and relates with students' achievement in exam. According to Horvat et al. (2015) components such as (1) average response waiting time, (2) feedback quality, (3) material completeness, (4) material clarity, (5) website userfriendliness, (6) cooperation diversity and (7) material quantity are more important to female students in online learning compare to male students. This statement gives a suggestion that further study may consider gender factor in analyze number of views and number of posts by students in MBP. 


\section{Conclusion}

One of main challenges in e-learning is keeping the students engaged and motivated during learning process (Moubayed et al., 2020). The study aimed to investigate students' engagement in MBP and identify the relation between number of views and numbers of posts by students to their achievement. Results of this study indicate that student who recorded higher number of views scored well in exam compare to the number of post in MBP. Based on the results, students view on peers' work, notes and contents increases students' achievement. Avci and Ergun (2019) said LMS activities such as interactive quizzes and digital instructional videos enable students to participate in their course in different way and foster students' participation. This shows that activities in MBP play main role to students to participate in learning and to gain knowledge. As a conclusion, this finding might be a reference not only to instructional developers who wish to design meaningful learning activities, but to online educators who facilitate content interactions among students to maximize students' engagement in online learning.

\section{Theoretical and Contextual Contribution of the Study}

LMS designed to promote learning through multiple features such as course content delivery, assessing and resulting, resource management and so on. But, students' engagement on LMS is more depends on how educator handled those features during learning process compare to the sophisticated features in LMS. Some educators lack of computer and information literacy skills, as well as their lack of information management skills cause the teaching and learning in LMS to be more course-centered rather than studentcentered (Habeeb, 2019). According to the findings, number of views by students in LMS related students' learning outcome. Therefore, educators should not only master the uses of LMS but also need to develop a critical perspective of their uses of LMS in variety modes to promote interesting learning environment and also students' engagement in online learning.

Other than that, Tseng et al. (2020) found that flexible thinking and growth mindset have a significant effort on online students' engagement. The study focused on postgraduate students based on their activities on LMS which reflect students' behavioral engagement. Emotional engagement of students which has been a part of online engagement still unexplored but influences their activities in LMS. Students in higher education came from various backgrounds need to have a flexible thinking and growth mindset to adapt themselves to new learning circumstances and the uses of advanced technology. This study found that Mathematics students' activity on number of posts less than number of views. This is due to the students who came from traditional learning background find difficult to adapt advanced online learning technology. It is important to point out students with fixed mindset and approach them in appropriate way to deliver teaching. This method helps them involve more in learning and improve their online engagement. The findings contribute to the development of effective instructional practices in online mathematics teaching. Educators should aware on the students' online engagement that can be the guidelines in designing their lesson.

\section{Acknowledgement}

This research was funded by the grant of Faculty of Education, Universiti Kebangsaan Malaysia GG-2020-016 


\section{References}

Akay, E., \& Gumusoglu, K. E. (2020). the Impact of Learning Management Systems on Students' Achievement in Language Exams. Turkish Online Journal of Distance Education, October, 206-222. https://doi.org/10.17718/tojde.803410

Aldiab, A., Chowdhury, H., Kootsookos, A., \& Alam, F. (2017). Prospect of eLearning in Higher Education Sectors of Saudi Arabia: A Review. Energy Procedia, 110(December 2016), 574-580. https://doi.org/10.1016/j.egypro.2017.03.187

Arthur-Nyarko, E., Agyei, D. D., \& Armah, J. K. (2020). Digitizing distance learning materials: Measuring students' readiness and intended challenges. Education and Information Technologies, 25(4), 2987-3002. https://doi.org/10.1007/s10639-019-10060-y

Avcı, Ü., \& Ergün, E. (2019). Online students' LMS activities and their effect on engagement, information literacy and academic performance. Interactive Learning Environments, O(0), 1-14. https://doi.org/10.1080/10494820.2019.1636088

Bassam, A., \& Alshorman, A. (2018). Attitudes of Faculty Members and Students towards the Use of the Learning Management System in Teaching and Learning. 17(3), 1-15.

Bolliger, D. U., \& Halupa, C. (2018). Online student perceptions of engagement, transactional distance, and outcomes. Distance Education, 39(3), 299-316. https://doi.org/10.1080/01587919.2018.1476845

Chen, Z., Lee, S., \& Garrido, G. (2018). Re-designing the structure of online courses to empower educational data mining. Proceedings of the 11th International Conference on Educational Data Mining, EDM 2018, 390-396.

Cortez, C. P. (2020). Blended, Distance, Electronic and Virtual-Learning for the New Normal of Mathematics Education : A Senior High School Student's Perception. 1(1), 1-6.

Deschaine, M. E., \& Whale, D. E. (2017). Increasing Student Engagement in Online. Journal of Educators Online, 14(1), 113-120. https://eric.ed.gov/?id=EJ1133612

Dumford, A. D., \& Miller, A. L. (2018). Online learning in higher education: exploring advantages and disadvantages for engagement. Journal of Computing in Higher Education, 30(3), 452-465. https://doi.org/10.1007/s12528-018-9179-z

Everett, D. R. (2015). Adding Value : Online Student Engagement. 13(November), 68-76.

Habeeb, K. T. (2019). E-learning platform / learning management system in education. International Journal of Reflective Research in Social Sciences, 2(1), 64-66.

Henrie, C. R., Bodily, R., Larsen, R., \& Graham, C. R. (2018). Exploring the potential of LMS log data as a proxy measure of student engagement. Journal of Computing in Higher Education, 30(2), 344-362. https://doi.org/10.1007/s12528-017-9161-1

Horvat, A., Dobrota, M., Krsmanovic, M., \& Cudanov, M. (2015). Student perception of Moodle learning management system: a satisfaction and significance analysis. Interactive Learning Environments, 23(4), 515-527. https://doi.org/10.1080/10494820.2013.788033

Karabıyık, C., Ufuk, U. (2019). the Relationship Between Student Engagement and Tertiary Level English Language Learners ' Achievement. International Journal of Education and Teaching (IOJET), 6(2), 281-293.

Kokoç, M. (2019). Flexibility in e-Learning: Modelling its Relation to Behavioural Engagement and Academic Performance. Themes in ELearning, 12, 1-16.

Kotsiantis, S., Tselios, N., Filippidi, A., \& Komis, V. (2013). Using learning analytics to identify successful learners in a blended learning course. International Journal of Technology Enhanced Learning, 5(2), 133-150. https://doi.org/10.1504/IJTEL.2013.059088

Lerche, T., \& Kiel, E. (2018). Predicting student achievement in learning management systems 
by log data analysis. Computers in Human Behavior, 89, 367-372. https://doi.org/10.1016/j.chb.2018.06.015

Lu, J., \& Law, N. W. Y. (2012). Understanding collaborative learning behavior from Moodle log data. Interactive Learning Environments, 20(5), 451-466. https://doi.org/10.1080/10494820.2010.529817

Marikar, M. F., \& Jayarathne, N. (2016). Effectiveness of MOODLE in Education System in Sri Lankan University. International Journal of Modern Education and Computer Science, 8(2), 54-58. https://doi.org/10.5815/ijmecs.2016.02.07

MacKenzie, L. M. (2019). Improving Learning Outcomes: Unlimited vs. Limited Attempts and Time for Supplemental Interactive Online Learning Activities. Journal of Curriculum and Teaching, 8(4), 36. https://doi.org/10.5430/jct.v8n4p36

Motz, B., Quick, J., Schroeder, N., Zook, J., \& Gunkel, M. (2019). The validity and utility of activity logs as a measure of student engagement. ACM International Conference Proceeding Series, 300-309. https://doi.org/10.1145/3303772.3303789

Moubayed, A., Injadat, M., Shami, A., \& Lutfiyya, H. (2020). Student Engagement Level in eLearning Environment: Clustering Using K-means Student Engagement Level in eLearning Environment: Clustering Using K-means. 3647. https://doi.org/10.1080/08923647.2020.1696140

Muhtia, A., Suparno, \& Sumardi. (2018). Blended Learning Using Schoology As an Online. 2nd English Language and Literature International Conference (ELLiC), 2, 171-175.

Ouadoud, M., Nejjari, A., Chkouri, M. Y., \& El-Kadiri, K. E. (2018). Learning Management System and the Underlying Learning Theories. Lecture Notes in Networks and Systems, 37, 732-744. https://doi.org/10.1007/978-3-319-74500-8_67

Pham, Q. T., \& Tran, T. P. (2020). The acceptance of e-learning systems and the learning outcome of students at universities in Vietnam. Knowledge Management and ELearning, 12(1), 63-84. https://doi.org/10.34105/j.kmel.2020.12.004

Redmond, P., Abawi, L., Brown, A., Henderson, R., \& Heffernan, A. (2018). An Online Engagement Framework for Higher Education. Online Learning Jurnal, 22(1), 183-204. https://doi.org/10.24059/olj.v22i1.1175

Safsouf, Y., Poirier, F., \& Mansouri, K. (2010). 1 U nderstand the B urden Knowledge Summary. 19.

Tseng, H., Kuo, Y. C., \& Walsh, E. J. (2020). Exploring first-time online undergraduate and graduate students' growth mindsets and flexible thinking and their relations to online learning engagement. Educational Technology Research and Development, 68(5), 22852303. https://doi.org/10.1007/s11423-020-09774-5

Vershitskaya, E. R., Mikhaylova, A. V., Gilmanshina, S. I., Dorozhkin, E. M., \& Epaneshnikov, V. V. (2020). Present-day management of universities in Russia: Prospects and challenges of e-learning. Education and Information Technologies, 25(1), 611-621. https://doi.org/10.1007/s10639-019-09978-0 